\title{
Fluorescent molecular sensor for the detection of cadmium in basil roots
}

\author{
Yulieth C. Reyes R ${ }^{1}$, Tahrima B. Rouf ${ }^{2}$, Omar E. Torres ${ }^{1}$, Edgar E. González ${ }^{1}$ \\ ${ }^{1}$ Pontificia Universidad Javeriana, Faculty of Engineering, Bogotá, 110231, Colombia \\ ${ }^{2}$ University of Oklahoma, Norman, Oklahoma- 73019, U.S.A \\ Corresponding Author: yreyes@javeriana.edu.co
}

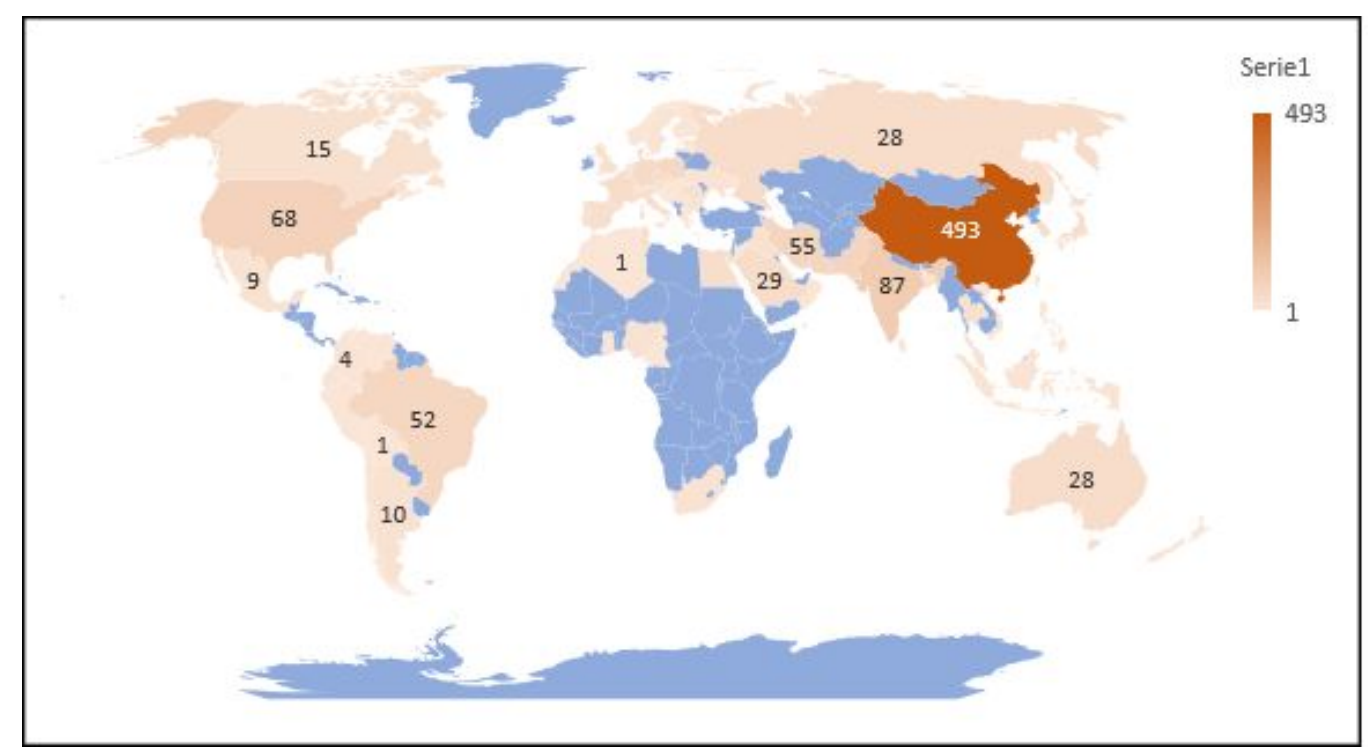

Figure S1. Scientific productivity by country according to the Cd problem in plants for human consumption. 